\title{
Editorial
}

\section{Things to look forward to in EBR}

\author{
Mark TEPFER \\ ICGEB Biosafety Outstation, Via Piovega 23, 31056 Ca' Tron di Roncade, Italy
}

\section{Changes in the EBR editorial team}

With the next issue of EBR, you will notice a few changes in the journal's editorial team. Some of these are in essence cosmetic, bringing the organization of the Editorial Board into conformity with the Bylaws of the ISBR (see http://www.isbr.info/). The other changes, which have to do with turnover on the Editorial Board, do merit presentation. Although the journal counts enormously on the commitment of the Board members, it is also necessary and normal that there be turnover on the Editorial Board. Starting with the next issue, we will have three new Board members, Alan McHughen, Terrance M. Hurley, and William Muir. The new members will undoubtedly bring both fresh ideas and broader expertise to the Board. At the same time, Per Pinstrup-Anderson, one of the founding members of the Board, has asked to step down. On the behalf of the entire EBR editorial team, I take this opportunity to thank Per for his work on the Board, and for his solidarity with the concept of EBR from a very early stage. Overall, the initial Editorial Board has done an excellent job, and I take this opportunity to thank them, and also David Andow and Klaus Ammann, co-founding Editors-in-Chief of EBR, for their ongoing commitment.

\section{New types of articles published in EBR}

From the beginning, EBR has primarily published original Research and Review Articles, with in addition an occasional Book Review and a regular series of Editorials. However, in this issue you will find the first examples of several new types of articles that EBR will also publish.

\section{Case Studies}

Case Studies will assemble and present data pertinent to the environmental risk assessment of the field release of a GMO. Unlike research articles, they will not contain appreciable unpublished results, and unlike review articles will not present a comprehensive overview of an area of research. Case Studies may present a national or regional perspective on a particular impact of dissemination of a particular GMO. Case Studies will undergo anonymous peer review, as is the case of research and review articles.

\section{Commentaries}

EBR has always - to a modest extent - published articles, such as Editorials and Book Reviews, in which the authors' opinion plays a greater role than in Research or Review Articles. In addition, EBR will now publish Commentaries, which are brief presentations of a novel point of view on a relatively precise question that is related to previously published results. For this type of article, if the initial submission is considered to be of interest to the readership of EBR, the manuscript will not be reviewed anonymously, but instead will go through a series of exchanges with one or more members of the Editorial Board, until it is considered to be compatible with the journal's editorial policy of scientific objectivity.

\section{Roundtables}

When a Commentary is based on the re-evaluation of data published by another group, it could become the starting point of a Roundtable. In this case, the Editors will invite other scientists, usually the authors of the article(s) presenting the initial data, to respond to the Commentary manuscript, or an expanded version of it. Roundtables provide an opportunity for exchange between scientists, which is based on a detailed, carefully thought out 


\section{Tepfer}

consideration of an issue of interest. Roundtable papers on a specific point will be published together as a group.

\section{The first EBR Case Study}

You will find in this issue a Case Study assembling the evidence concerning whether or not the pale grass blue butterfly (Pseudozizeeria maha (Kollar)) is an appropriate indicator species for studying non-target effects of $B t$ maize in Japan (Wolt et al., 2005). Among the points presented, two observations are particularly pertinent. One is that the geographic range of the butterfly and its host plant only coincide to a limited extent with the areas of maize cultivation in Japan. The other is that the butterfly feeds only on the lower side of the leaves of its host plant, and thus would be exposed to very limited amounts of $B t$ maize pollen, even when the host and $B t$ maize would grow in close proximity. This suggests that this butterfly would not be expected to be at risk from $B t$ maize pollen, and the simple conclusion would be that it is not an appropriate indicator for monitoring the effects of $B t$ maize on non-target Lepidoptera. However, this does raise the difficult issue of how to proceed if - as seems to be the case in Japan no Lepidopteran species has all the characteristics required to be a valid indicator for non-target effects in the field, such as: sensitivity to $B t$ toxin, exposure to it via $B t$ maize, sufficient abundance for changes in population size to be validated statistically.

\section{The first EBR Roundtable}

This issue of EBR contains the journal's first Roundtable, composed of two papers concerning the controversial issue of the presence/absence of transgenes in maize landraces in Mexico. This story began with the paper of Quist and Chapela (2001) showing that transgene sequences could be detected by PCR performed on DNA extracted from even a few ears of maize growing in the mountainous Sierra Juárez region of Oaxaca. Although there have been no peer-reviewed publications confirming these results, the presence of transgenes was supported by studies by the Mexican government. In more recent developments, Ortiz-García et al. (2005a) published a paper describing a large-scale study aimed at following up on the presence of transgenes in maize in the same region of Mexico in 2003 and 2004, but in fact they were unable to detect the expected transgenes. The first paper of the EBR roundtable (Cleveland et al., 2005) provides a critical re-examination of the data of OrtizGarcía et al. (2005a) on the absence of detectable transgenes in the Sierra Juárez region of Oaxaca. Cleveland et al. make several interesting points, among which that the sampling strategy was not optimal for evaluating the frequency of transgenes in the local maize populations, and also that if what they consider to be more appropriate statistical tools are used, the threshold of detection is considerably higher than originally proposed by Ortiz-García et al. (2005a). In response to this, in the second roundtable paper, Ortiz-García et al. (2005b) accept many of the suggestions of the article by Cleveland et al., but also use the techniques of metaanalysis on their data, and through this support their conclusion that the threshold of detection in their results is nearly as low as reported in their initial paper. What do we readers gain from this exchange? First, a more complete analysis of a unique data set of great importance in a controversial area; second, a better appreciation of the statistical tools than can be used to analyze this type of data; third, a clearer idea of how sampling strategies should be designed for determining (trans)gene frequencies at the population or regional levels; and last, a rather puzzling vision of the subjectivity of the judgment of how low a threshold should be for the absence of detection of transgenes to be the equivalent to their simple absence.

\section{REFERENCES}

Cleveland DA, Soleri D, Aragón Cuevas F, Crossa J, Gepts $\mathbf{P}$ (2005) Detecting (trans)gene flow to landraces in centers of crop origin: lessons from the case of maize in Mexico. Environ. Biosafety Res. 4: 197-208

Ortiz-Garcia S, Ezcurra E, Schoel B, Acevedo F, Soberon J, Snow AA (2005a) Absence of detectable transgenes in local landraces of maize in Oaxaca, Mexico (2003-2004). Proc. Natl. Acad. Sci. USA 102: 12338-12343

Ortiz-García S, Ezcurra E, Schoel B, Acevedo F, Soberón J, Snow AA (2005b) Reply to Cleveland et al.'s "Detecting (trans)gene flow to landraces in centers of crop origin: lessons from the case of maize in Mexico". Environ. Biosafety Res. 4: 209-215

Quist D, Chapela IH (2001) Transgenic DNA introgressed into traditional maize landraces in Oaxaca, Mexico. Nature 414: $541-543$

Wolt JD, Conlan CA, Majima K (2005) An ecological risk assessment of Cry1F maize pollen impact to pale grass blue butterfly. Environ. Biosafety Res. 4: 243-251 